\title{
From Acceptability to Acceptance: Does Experience with the Product Influence User Initial Representations?
}

\author{
Nicolas Martin ${ }^{1,2}$, Éric Jamet ${ }^{2}$, Séverine Erhel $^{2}$, Géraldine Rouxel ${ }^{2}$ \\ ${ }^{1}$ Uses \& Acceptability Lab, b $<>$ com, France \\ nicolas.martin@b-com.com \\ ${ }^{2}$ CRPCC, University of Brittany, France \\ \{eric.jamet, severine.erhel, geraldine.rouxel\}@univ-rennes2.fr
}

\begin{abstract}
Adopting a product can be seen as a process that implies some repeated use influencing either positively or negatively judgment over time. Indeed, product judgement is likely to evolve over time and influence the intention to continue using. At yet, little research is avalaible on the evolution of product jugdgement with use. In this paper, we examined the evolution of User eXperience (UX) and affective-motivational factors between evaluation before and after use. Results showed that interaction with the product significantly influences initial representations with, in our study, more negative judgments after use. Moreover, using Expectation-Disconfirmation Theory, significant influences of initial evaluations (i.e. judgement before use) and disconfirmation (i.e. difference between judgement after and before use) were found on behavioral intention after use.
\end{abstract}

Keywords: Acceptability, Acceptance, User eXperience, UX,

Comparison Before-After Use, Expectation-Disconfirmation Theory

\section{Introduction}

Product adoption is a long term process: it starts from user representations before use and evolves over time with use. Thereby, understanding factors that lead to continued use is a critical point for companies that develop technological products. Consequently, research has been conducted to better understand technology use, with the aim to identify facilitating or inhibitory factors to the adoption of a technological product. Thus, a distinction is made between acceptability (the judgment toward a technology before use [1]) and acceptance (the judgment and the behavioral reactions toward a product after use [1]). Although this distinction exists, majority of research is centered on acceptance. In the following study, we explored the difference between evaluation before and after use in the context of mobile application. Moreover, we tried to understand the factors that explain the pursuit of use of a mobile application through the framework of EDT. 


\subsection{Acceptance, User eXperience and Affective-Motivational Factors}

To understand product adoption, two main models are commonly used: TAM [2] and UTAUT [3]. According to these models, behavioral intention derives from the perception of functional qualities (especially usability and usefulness). Although these models have been tested in numerous studies $[4,5]$, some limits are now widely recognized. First, inside theoretical field of User eXperience (UX) it was demonstrated that users perceive product beyond their functional qualities [6]. Thereby, UX is defined as "a person's perceptions and responses that result from the use and/or anticipated use of a product, system or service" [7] and incorporates functional and nonfunctional qualities as predictors of overall judgement [8]. Second, several researchers has highlighted that product's judgement is more complex than a rational evaluation based on quality criteria [9]. Thus, according to previous research, factors as selfimage [e.g. 10], intrinsic motivation [e.g. 11] and social influence [e.g. 5] are good predictors of acceptance in addition to usability and usefulness. Nevertheless, aside from a few studies $[12,13]$, research is only centered on judgement after use. Thereby, we proposed to evaluate the evolution of functional, nonfunctional and affectivemotivational variables between evaluation before and after use. Moreover, to understand evolution from acceptability (i.e. judgment before use) to acceptance (i.e. judgement after use), we tried to use the framework of Expectation-Disconfirmation Theory (EDT) [14].

\subsection{Expectation-Disconfirmation Theory}

To our knowledge, only EDT proposed a framework to explain continued usage [e.g. 12, 13]. Based on Cognitive Dissonance Theory [15], this framework depicts a process model of individual behavior with product over time. According to EDT [14], when consumers purchase a product, they have some prior information on the product (i.e. initial expectations) based on second-hand information, such as vendor claims [12]. Over time and use, users gain more information and experience on the product [13]. Thereby, they compare their prior beliefs to new information gained with experience. If there is some dissonance (difference between one's cognition and reality [12]), they can revise their attitudes and behaviors (e.g. pursuit of use). Lastly, disconfirmations (difference between expectation and reality) and initial expectations determine user satisfaction which explains continued usage [13, 14].

According to previous studies, EDT is a useful framework to understand ongoing use $[12,13]$. In the following study, we proposed to rely on EDT framework to study the evolution from acceptability to acceptance. The originality of our work is to include UX and affective-motivational factors in evaluation before and after use.

\subsection{Current Study}

Today, many people have a smartphone and consequently use mobile applications. Thereby, understanding adoption of applications is a major concern for developers. Nevertheless, in context of mobile application, judgement before use is essential. 
Indeed, to choose to install an application, individuals must evaluate it before they can test it. However, to our knowledge, influence of UX and affective-motivational factors on judgement before use has not studied. Thereby, in current study, we evaluated difference between judgement before and after use on usefulness, usability, trust, stimulation, self-image, intrinsic motivation and social influence. Moreover, we used EDT framework to explore adoption of mobile applications. This framework seems to be adapted to mobile application context. Thus, before selecting and downloading an application, individuals have access to little information as the description of the application. From this information, individuals have to form their judgement and attitude toward the application. As soon as the individuals decide to install the application, they will be able to compare their prior judgments with the new representations of the actual application. According to previous studies, individuals should decide to continue their use by taking into account their initial expectations and disconfirmations (difference between expectations and reality).

\section{Method}

\subsection{Material}

To test the differences between pre-usage and after-usage on judgement of a mobile application, we have selected a sleeping tracker application "Sleep Better (C)"[16]. This application was selected because it is simple, free, designed for repeated use and relatively distributed.

\subsection{Measures}

To evaluate the influence of UX and affective-motivational factors on acceptability/acceptance, the following dimensions were measured:

- Assessment of UX factors: Usefulness (4 items), Usability (4 items), Stimulation (4 items) and Trust (3 items)

- Assessment of affective-factors: Motivation (5 items), Self-image (4 items) and Social Influence (3 items)

- Assessment of acceptability/acceptance: Intention to use (4 items)

Some items were constructed specifically for this study and others were based on existing questionnaires as UTAUT [3], Attrackdiff [8] and Engagement Scale [17]. For each item, participants had to answer on an 11 points likert scale (from 0 to 10). Position of each item in the questionnaire was randomly delivered to avoid effects related to order of the items [18]. Lastly, according to EDT, intention to continue using is based on initial expectations (i.e. evaluations before use) and disconfirmations (i.e. differences between expectations and reality). Expectations are measured by evaluating each dimension before use. Disconfirmations are evaluated by calculating the difference between the assessment after and before use for each dimension. 


\subsection{Procedure}

Study involved four main steps: 1/ The participants filled out the questionnaire before use after reading a brief presentation of the application. This presentation included text and pictures proposed by Runtastic on market app (Google Play). 2/ At the end of the first questionnaire, participants could choose to test the application and participate in the rest of the study. To take part in the following study, participants had to provide their email address. 3/ Participants who gave their email address received explanations for installing the application and a link for the post-use questionnaire. 4/ After at least one night of use, the participants filled out the after use questionnaire. Only individuals who completed both evaluations were included in our analyses. Data between survey before and after use are linked anonymously with a unique code.

\subsection{Participants}

318 participants have completed the questionnaire before use. Nevertheless, only 47 participants (39 women), who never used the "sleep better" app, have completed evaluations before and after use. Analyses are realized on these participants. They were recruited on social network: Facebook, Twitter and Linkedin. The average age is 29.19 years $(\mathrm{SD}=10.72)$.

\section{Results}

To test the effect of use on judgment, we computed comparisons between evaluation before and after user for each dimension. Since evaluation before and after use are completed by the same individuals, we used a statistical method that takes into account non-independence: mixed model [19]. Results (see Table 1) indicated significant decrease between evaluation before and after use on behavioral intention, usefulness, self-image and social influence.

Table 1. Descriptive statistics (mean and standard deviation) and comparison for evaluation before and after use

\begin{tabular}{|c|c|c|c|}
\hline Dimension & Before Use & After Use & Difference \\
\hline Behavioral Intention & $6.59(2.60)$ & $4.89(2.95)$ & $\chi^{2}(1)=17.00, p<.001$ \\
\hline Usefulness & $6.74(2.19)$ & $5.13(2.41)$ & $\chi^{2}(1)=25.57, p<.001$ \\
\hline Usability & $7.58(1.61)$ & $7.73(1.95)$ & $\chi^{2}(1)=.36, \mathrm{NS}$ \\
\hline Stimulation & $6.80(2.24)$ & $6.55(1.74)$ & $\chi^{2}(1)=.72, \mathrm{NS}$ \\
\hline Trust & $5.56(1.96)$ & $4.96(2.40)$ & $\chi^{2}(1)=3.42, \mathrm{NS}$ \\
\hline Self-Image & $3.77(2.03)$ & $2.73(1.96)$ & $\chi^{2}(1)=14.58, p<.001$ \\
\hline Motivation & $5.54(2.19)$ & $5.18(1.87)$ & $\chi^{2}(1)=1.47, \mathrm{NS}$ \\
\hline Social Influence & $4.94(2.32)$ & $2.75(2.29)$ & $\chi^{2}(1)=33.29, p<.001$ \\
\hline
\end{tabular}

According to EDT, carry on using is based on initial representations (i.e. evaluation before use) and disconfirmation (i.e. difference between initial representations 
and reality) $[12,13]$. To test theses hypotheses, we computed a multiple regression on behavioral intention after use. Results indicated significant influences of initial evaluations of usefulness $(\beta=.85, p<.01)$, usability $(\beta=.55, p<.01)$ and stimulation $(\beta=$ $-.49, p<.05)$. We found also an influence of disconfirmations for usefulness $(\beta=.50$, $p<.05)$, usability $(\beta=.36, p<.05)$, stimulation $(\beta=-.47, p<.05)$ and trust $(\beta=.35$, $p<.05)$. Lastly, among the affective-motivational factors, only intrinsic motivation seem to have an effect $(\beta=.68, p<.01)$ on behavioral intention after use.

Lastly, we compared two models that explained behavioral intention after use: one model including only variables of TAM and our model introducing UX and affectivemotivational factors. Result indicated a significant increasing $(F(7,47)=2.69$, $p<.05)$ of the explained variance for our model $\left(R^{2}=.67 \mathrm{vs} .74\right)$.

\section{Discussion and Conclusion}

Consistently with previous studies [12, 13], significant influences of use were found on evaluation of several variables: behavioral intention and perceptions of usefulness, trust, self-image and social influence decrease after use. Moreover, we used EDT framework to understand the adoption of this mobile application. To obtain a deeper comprehension than previous studies, we evaluated functional and nonfunctional qualities but also affective-motivational factors. In agreement with EDT, we evaluated the influence of prior judgement and disconfirmation on intention to carry on using. Results showed three main results: firstly, prior perceptions of usefulness, usability and stimulation influence intention to continue using. Secondly, disconfirmation (difference between initial perception and reality) on usefulness, usability, stimulation and trust are significant predictors of intention to continue using. Lastly, the intrinsic motivation is also a significant predictor of intention to continue using. In others words, the initial perceptions of qualities and the difference between these perceptions and reality influenced the intention to continue to use the product. In summary, take an interest to acceptability by evaluating before use functional, nonfunctional qualities and affective-motivational factors seems to be an interesting approach to understand product adoption and continue using.

Nevertheless, several limits can be addressed. Firstly, the sample was relatively small. To confirm our results, it is necessary to carry out new studies on larger samples. Secondly, only one application, which has good functional qualities according to users, was evaluated. For a deeper comprehension of judgement evolution, we should conduct new studies on more applications with several levels of qualities. Lastly, it is necessary to conduct longitudinal study for studying long term use.

Acknowledgements. This work was carried out within the Institute of Technological Research $\mathrm{b}<>c \mathrm{com}$ and it received support from the French government under the program Future Investments bearing reference ANR-07-A0-AIRT. 


\section{$5 \quad$ References}

1. Schuitema, G., Steg, L., Forward, S.: Explaining differences in acceptability before and acceptance after the implementation of a congestion charge in Stockholm. Transp. Res. Part Policy Pract. 44, 99-109 (2010).

2. Davis, F.D.: Perceived Usefulness, Perceived Ease of Use, and User Acceptance of Information Technology. MIS Q. 13, 319-340 (1989).

3. Venkatesh, V., Morris, M., Davis, G., Davis, F.: User Acceptance of Information Technology: Toward a Unified View. Manag. Inf. Syst. Q. 27, (2003).

4. King, W.R., He, J.: A meta-analysis of the technology acceptance model. Inf. Manage. 43, 740-755 (2006).

5. Taiwo, Y.A., Downe, A.G.: The Theory of user Acceptance and Use of Technology (UTAUT): A meta-analytic review of empirical findings. J. Theor. Appl. Inf. Technol. 49, (2013).

6. Bargas-Avila, J.A., Hornbaek, K.: Old Wine in New Bottles or Novel Challenges? A Critical Analysis of Empirical Studies of User Experience. In: Proceedings of the SIGCHI Conference on Human Factors in Computing Systems. pp. 2689-2698. ACM, New York, NY, USA (2011).

7. ISO: ISO 9241-210:2010 - Ergonomics of human-system interaction - Part 210: Humancentred design for interactive systems. (2010).

8. Hassenzahl, M., Diefenbach, S., Göritz, A.: Needs, affect, and interactive products-Facets of user experience. Interact. Comput. 22, 353-362 (2010).

9. Venkatesh, V., Morris, M.G.: Why Don't Men Ever Stop to Ask for Directions? Gender, Social Influence, and Their Role in Technology Acceptance and Usage Behavior. MIS Q. 24, 115-139 (2000).

10. van Schaik, P., Ling, J.: An integrated model of interaction experience for information retrieval in a Web-based encyclopaedia. Interact. Comput. 23, 18-32 (2011).

11. Lee, M.K.O., Cheung, C.M.K., Chen, Z.: Acceptance of Internet-based learning medium: the role of extrinsic and intrinsic motivation. Inf. Manage. 42, 1095-1104 (2005).

12. Bhattacherjee, A., Premkumar, G.: Understanding Changes in Belief and Attitude toward Information Technology Usage: A Theoretical Model and Longitudinal Test. MIS Q. 28, 229-254 (2004).

13. Venkatesh, V., Thong, J.Y.L., Chan, F.K.Y., Hu, P.J.-H., Brown, S.A.: Extending the two-stage information systems continuance model: incorporating UTAUT predictors and the role of context. Inf. Syst. J. 21, 527-555 (2011).

14. Oliver, R.L.: A Cognitive Model of the Antecedents and Consequences of Satisfaction Decisions. J. Mark. Res. 17, 460 (1980).

15. Festinger, L.: A Theory of Cognitive Dissonance. Stanford University Press (1962).

16. Sleep Better App, https://www.runtastic.com/en/apps/sleepbetter.

17. O'Brien, H.L., Toms, E.G.: Examining the generalizability of the User Engagement Scale (UES) in exploratory search. Inf. Process. Manag. 49, 1092-1107 (2013).

18. Benton, J.E., Daly, J.L.: A Question Order Effect in a Local Government Survey. Public Opin. Q. 55, 640-642 (1991).

19. Bates, D., Mächler, M., Bolker, B., Walker, S.: Fitting Linear Mixed-Effects Models Using lme4. J. Stat. Softw. 67, 1-48 (2015). 